\title{
ASSESSMENT OF GENETIC STRUGTURE OF THE ENDANGERED FOREST SPECIES BOSWELLIA SERRATA POPULATION IN CENTRAL INDIA
}

\author{
Vaishnav $\mathbf{V}^{1,2}$, Mahesh $\mathbf{S}^{3} \&$ Kumar $\mathbf{P}^{4, *}$ \\ ${ }^{1}$ CSIR-National Botanical Research Institute, Lucknow, 226001 \\ ${ }^{2}$ Institute of Forest Productivity, Ranchi, 835303 \\ ${ }^{3}$ National Institute for Research in Tribal Health, Jabalpur, Madhya Pradesh, 482001 \\ ${ }^{4}$ Tropical Forest Research Institute, Jabalpur, Madhya Pradesh, 482021 \\ *pramod_kt@rediffmail.com \\ Submitted April 2018; accepted August 2018
}

\begin{abstract}
Boswellia serrata, a commercially important species for its pulp and pharmaceutical properties was sampled from three locations representing its natural distribution in central India for genetic characterisation through 56 RAPD + 42 ISSR loci. The wood fibre dimensions measured for morphometric characterisation confirmed $11.36 \%$ variation in length and $8.75 \%$ variation in width, indicating its fitness for local adaptation. Bayesian and non-Bayesian approach based diversity measures resulted moderately within population gene diversity $(0.26 \pm 0.17)$, Shannon's information index $(0.40 \pm 0.22)$ and panmictic heterozygosity $(0.28 \pm$ $0.01)$. A high estimate for genetic differentiation measures i.e. $\mathrm{G}_{\mathrm{ST}}(0.31), \mathrm{G}_{\mathrm{ST}}-\mathrm{B}(0.33 \pm 0.02)$ and $\theta$-II $(0.45)$ led to distinct clusters of sampled genotypes, representing their regional variability due to limited gene flow and total absence of natural regeneration. This study reports the first investigation of the species for its molecular characterisation emphasising the urgent need for a genetic improvement program for in-situ/ ex-situ conservation and sustainable commercialisation.
\end{abstract}

Keywords: Burseraceae, $\theta$-statistics, Shannon's information index, genetic improvement

\section{INTRODUCTION}

Boswellia serrata (Burseraceae), commonly known as salai guggul or Indian frankincense (olibanum indicum) is a commercially important deciduous tree of India (Shah et al. 2008). It is found in regions having rainfall between $500 \mathrm{~mm}-$ $2000 \mathrm{~mm}$ and temperature up to $45^{\circ} \mathrm{C}$. The species can thrive in the poorest and shallowest soils (Bhat et al. 1952). In India, it is distributed in the states of Rajasthan, Maharashtra, Madhya Pradesh, Karnataka and Chhattisgarh (Pawar et al. 2012). The oleo-gum-resin of the tree contains boswellic acid, which is effective for the treatment of inflammatory disorders, arthritis, cardiovascular diseases, diarrhea, dysentery and other skin diseases (Khare 2004, Ammon 2006). Apart from these medicinal values, the resin of the species was found to be a more effective sizing agent in papermaking than resin obtained from Pinus species (Sharma et al. 1985). This wood quality for pulp making led to the establishment of the first paper mill in Nepanagar of Madhya Pradesh, India, as the region was naturally occupied by a wide range of the species (Khan 1972).
The species is highly out-crossing, supported by self-incompatibility to selfing (Sunnichan et al. 2005). However, its poor fruit setting $(2.6 \%-10 \%)$ under open pollination condition, inadequate production of viable seeds and scanty seed germination $(10 \%-20 \%)$ limit the distribution of the species in nature (Ghorpade et al. 2010). The species population has been harvested for frankincence (Sharma 1983). The scarcity of protocols to regenerate the species through seeds and clones makes mass multiplication difficult (Purohit et al. 1995). This situation resulted in declined abundance of the species, and listed as endangered by the International Union for Conservation of Nature (IUCN). Therefore, the available natural patches of the species require keen attention for both in-situ and ex-situ conservation with actual knowledge of available genetic resources of the species, for management and breeding objectives.

Information on actual genetic variability and the cryptic number of the differentiated genetic resource are important aids for its conservation and genetic improvement. For such purposes, 
DNA based markers are of great value; unlike morphometric traits, the molecular markers are independent of environmental influence and assessable at any growth stage. Among the various molecular markers employed to assess diversity studies, PCR-based dominant markers such as random amplified polymorphic DNA (RAPD) and inter-simple sequence repeat (ISSR) have become popular due to their polymorphism and discrimination power, as their application does not need any prior sequence information (Zietkiewiez et al. 1994). These primer systems have been successfully applied for genetic characterisation of tropical tree species populations (Ansari et al. 2012, Abuduli et al. 2016, Vaishnav \& Ansari 2018). Bayesian statistics has been extended to dominant markers for precise estimates of population genetic hierarchies equivalent to those obtained with codominant markers, circumventing inbreeding estimate within the population (Holsinger et al. 2002). Therefore, the present investigation was conducted to differentiate the morphometric and genetic variability exhibited by the natural population of B. serrata in three agro-climatic regions of central India, applying dominant marker system.

\section{MATERIAL AND METHODS}

\section{Population sampling}

The distribution of $B$. serrata was obtained from the old forest working plans of the forest department of Chhattisgarh, classified in three agro-climatic zones viz. Northern Hills, Chhattisgarh plain and Bastar plateau (Table 1). The forests of these agro-climatic regions were visited during July to September 2014 to collect samples from 20 trees of each region within the natural distribution of $B$. serrata, with inter-tree distance of $100 \mathrm{~m}$ along the latitude (Figure 1). The girth at breast height (gbh) was measured using a measuring tape. A wood radial core sample was extracted from each tree at breast height $(1.34 \mathrm{~m})$ and stored in a tube with $40 \%$ formaldehyde. A leaf sample was also collected from each tree. The samples were transported to the laboratory in a cryo-box.

\section{Measurement of wood fibre dimensions}

In the laboratory, the wood samples were macerated as described by Mahesh et al. (2015). Five slides were prepared for each tree; the wood fibre length (WFL) and width (WFW) were measured using a compatible program integrated with compound microscope.

\section{DNA isolation and amplification}

The DNA from the leaf samples was isolated following modified cetyl trimethylammonium bromide (CTAB) method (Deshmukh et al. 2007). To select the reproducible markers, 10 RAPD and 10 ISSR primers were cross-amplified for 12 genotypes of the species (four from each region) and finally, five from each RAPD and ISSR markers were selected based on their polymorphism and reproducibility for the final amplification of all 60 genotypes (Table 3). For RAPD/ISSR amplification, the final PCR reaction mixture, $15 \mu \mathrm{L} / 10 \mu \mathrm{L}$, contained $50 \mathrm{ng} / 40 \mathrm{ng}$ genomic DNA, $0.66 \mu \mathrm{M} / 0.8 \mu \mathrm{M}$ of primers, $0.2 \mathrm{mM} / 0.1 \mathrm{mM}$ of dNTP mix, $1.5 \mathrm{mM} / 2.5 \mathrm{mM} \mathrm{MgCl}_{2}, 1 \mathrm{X}$ buffer with $\mathrm{KCl}$

Table 1 Geo-climatic conditions of the three regions of natural distribution of B. serrata populations sampled for the investigation

\begin{tabular}{|c|c|c|c|c|c|c|c|}
\hline \multirow[t]{2}{*}{ Regions } & \multirow[t]{2}{*}{$\begin{array}{l}\text { Agro-climatic } \\
\text { zones }\end{array}$} & \multicolumn{2}{|c|}{ GPS coordinate ranges } & \multirow[t]{2}{*}{ Altitude (m) } & \multicolumn{2}{|c|}{$\begin{array}{c}\text { Mean annual } \\
\text { temperature }\left({ }^{\circ} \mathrm{C}\right)\end{array}$} & \multirow{2}{*}{$\begin{array}{c}\text { Annual } \\
\text { precipitation } \\
(\mathrm{mm})\end{array}$} \\
\hline & & Latitude $(\mathrm{N})$ & Longitude (E) & & Min & Max & \\
\hline $\begin{array}{l}\text { Dhamtari } \\
\text { (DT) }\end{array}$ & $\begin{array}{l}\text { Chhattisgarh } \\
\text { Plain }\end{array}$ & $\begin{array}{l}20.37861- \\
20.40511\end{array}$ & $\begin{array}{l}81.96636- \\
81.98122\end{array}$ & $445.80 \pm 5.44$ & $21.60 \pm 5.22$ & $33.02 \pm 3.56$ & $1488 \pm 0$ \\
\hline $\begin{array}{l}\text { Narayanpur } \\
(\mathrm{NP})\end{array}$ & Bastar Plateau & $\begin{array}{l}19.71365- \\
19.71586\end{array}$ & $\begin{array}{l}81.19447- \\
81.19836\end{array}$ & $595.60 \pm 21.39$ & $20.80 \pm 5.22$ & $32.40 \pm 3.36$ & $1628 \pm 0$ \\
\hline $\begin{array}{l}\text { Sarguja } \\
\text { (SG) }\end{array}$ & Northern Hills & $\begin{array}{l}23.39300- \\
23.39446\end{array}$ & $\begin{array}{l}83.46277- \\
83.46783\end{array}$ & $619.75 \pm 7.15$ & $19.02 \pm 6.35$ & $31.02 \pm 4.07$ & $1670 \pm 0$ \\
\hline
\end{tabular}

$\pm=$ standard deviation $(\mathrm{SD})$ 


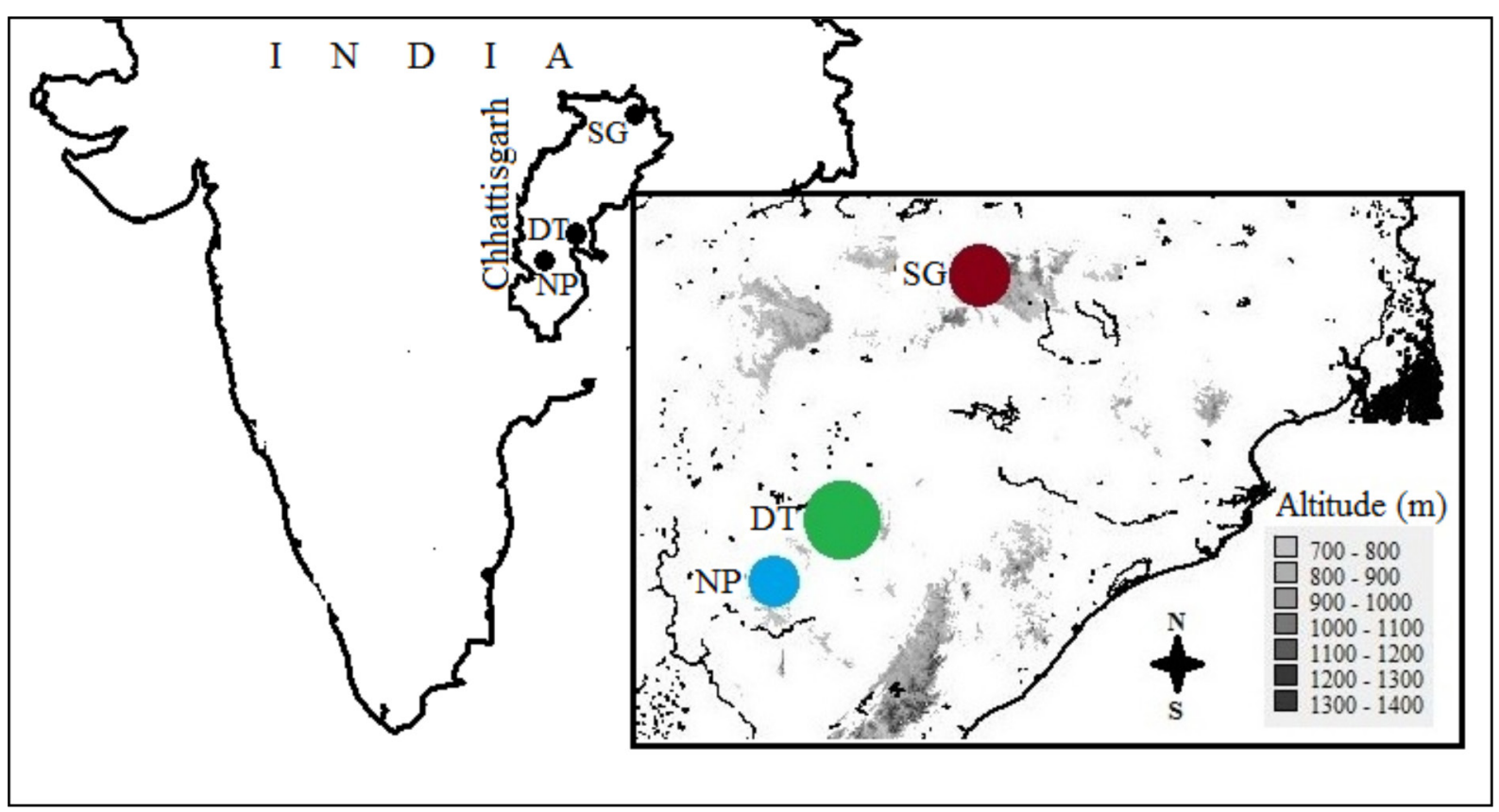

Figure 1 Three regions i.e. Sarguja (SG), Dhamatri (DT) and Narayanpur (NP) of natural distribution of B. serrata from central Indian region (Chhattisgarh) were sampled for investigation; every location represents distinct agro-climatic zone namely Northern hills (SG), Chhattisgarh plain (DT) and Bastar plateau (NP); an inset view of altitudinal variation is given in the box, size differences among the location's legend dot depicts differences in gene diversity of the species estimated by employing dominant markers

and 1 unit of Taq polymerase. The PCR assay included an initial 4 minutes denaturation step at $94{ }^{\circ} \mathrm{C}$ followed by 35 cycles of $30 \mathrm{~s}$ at $94{ }^{\circ} \mathrm{C}$, $30 \mathrm{~s}$ at the annealing temperature of $35^{\circ} \mathrm{C} / 50^{\circ} \mathrm{C}$, 45 s extension at $72^{\circ} \mathrm{C}$, followed by a final extension of 5 minutes at $72{ }^{\circ} \mathrm{C}$. The amplified products were electrophoresed on $1.5 \%$ agarose gel containing $0.5 \mu \mathrm{g} / \mathrm{ml}$ ethidium bromide (EtBr) in $0.5 \mathrm{X}$ TBE $(\mathrm{pH} \mathrm{8.0)}$. The separation was carried out by applying constant $100 \mathrm{~V}$ for 3 hours. The fractionated amplified products on agarose gel were visualised on gel documentation system under UV light. To avoid homology, the amplification profile of all sixty genotypes was evaluated through the molecular weight of the bands for each primer and the bands were scored in a Microsoft Excel sheet in binary data format.

\section{Data analysis}

The measures of central tendency and the coefficient of variation (CV) were calculated for gbh, WFL and WFW. A genetic profile of 60 genotypes on 10 markers was generated and analysed following both band-based and allele frequency-based approaches as described by Bonin et al. (2007). The information from the markers was evaluated, estimating mean allelic frequency (AF), gene diversity (GD) and polymorphic information content (PIC) using POWERMARKER v 3.1 program (Liu \& Muse 2005). Resolving power (RP) of the markers was calculated as described by Prevost and Wilkinson (1999).

The genetic variability and differentiation of the sampled population were evaluated with both non-Bayesian and Bayesian approaches. The program POPGENE v 1.32 (Yeh et al. 1999) was applied for the non-Bayesian estimates of genetic diversity measures i.e. Nei's gene diversity (GD), Shannon's information index (I) and the percentage of polymorphism $(\mathrm{P} \%)$ for each location, and $\mathrm{G}_{\mathrm{ST}}$ was calculated to evaluate the level of genetic differentiation. The genetic relationship among the genotypes was calculated based on Jaccard's genetic similarity coefficient using the program DARWIN v 5.0 (Perrier \& Jacquemoud-Collet 2006). The principal coordinate analysis (PCoA) was performed to cluster the genotypes in different axes using the program GENALEX v 6.5 (Peakall \& Smouse 2012). Analysis of molecular variance 
(AMOVA) was performed using the program ARLEQUIN v 3.11 to estimate the hierarchical variation (Excoffier \& Lischer 2010). The isolation by distance (IBD) was calculated from the correlation coefficient between two pairwise matrices of genetic and geographical distances among genotypes, through Mantel's test performed using the program ALLELES IN SPACE in independent runs (with and without logarithmic transformation) on 10,000 permutations (Miller 2005).

For Bayesian approach based genetic estimates, the $\theta$-statistics (viz. $\theta$-I, $\theta$-II, $\theta$-III and $\mathrm{G}_{\mathrm{ST}_{\mathrm{T}}} \mathrm{B}$ ) implemented by using the program HICKORY v 1.1) were preferred (Holsinger \& Lewis 2007). It allowed direct estimation of genetic differentiation measure $\left(\mathrm{F}_{\mathrm{ST}}\right)$ from dominant markers without assumption of prior knowledge of the extent of inbreeding and Hardy Weinberg Equilibrium (HWE), even within populations of small size and number. Region-wise panmictic heterozygosity $(\mathrm{Hs})$ and total panmictic heterozygosity $(\mathrm{Ht})$ were also estimated. All these estimations were performed with 50,000 steps of burn-in, 500,000 replicates and 20 thinnings, using the best-suited model for the data amongst all four models (viz. full, $\mathrm{f}=0, \theta=0$ and f-free models), implemented based on minimum deviance information criterion (DIC) value as described by Spiegelhalter et al. (2002). To determine the most suitable number of cryptic populations (K) for the data, the program STRUCTURE v 2.3.1 was used (Pritchard et al. 2000). The model applied combinations of admixture/ no-admixture with correlated/independent allele frequencies among the samples, on 100000 burn-in and 1000000 MCMC repeats, with three-runs from $K=1$ to $K=9$, for number of $\mathrm{K} 2 \leq \mathrm{K} \leq 8$. The most suitable model and the best-suited $\mathrm{K}$ was determined based on the highest delta-K value resulted by using the online program STRUCTURE HARVESTER (Earl and Von Holdt 2012).

\section{RESULTS}

\section{Variation in wood fibre dimension}

The WFL of the species ranged between $0.803 \mathrm{~mm}$ to $1.397 \mathrm{~mm}$ with an average of 0.968 $\pm 0.11 \mathrm{~mm}(11.36 \% \mathrm{CV})$, and the WFW of the species ranged between $0.019 \mathrm{~mm}$ to $0.030 \mathrm{~mm}$ with average of $0.025 \pm 0.002 \mathrm{~mm}(8.75 \% \mathrm{CV})$. Both traits followed normal distribution and no significant correlation was observed between them. Both the WFL and WFW were evenly distributed on standard deviation $(\sigma)$ based classes, and no significant variation was observed among the locations based on WFL and WFW (Table 2).

\section{Genetic informativeness of markers}

The five RAPD primers amplified 826 bands and 56 loci (14.75 bands/locus). The diversity measures, $\mathrm{AF}$ and GD, were $0.81 \pm 0.065$ and $0.27 \pm 0.075$ respectively. The PIC and RP were $0.22 \pm 0.054$ and $5.51 \pm 3.17$ subsequently (Table $3)$. For RAPD markers, the diversity measures and discriminatory power measures were found insignificant $(p<0.05)$ in linear correlation. The five ISSR primers amplified 1004 bands for 42 loci (23.90 bands/locus). In a significant linear correlation $(\mathrm{p}<0.01)$ to each other; $\mathrm{AF}$ was $0.76 \pm 0.068$ and the GD was $0.33 \pm 0.073$. The PIC and the RP were $0.27 \pm 0.052$ and $6.69 \pm 1.69$ subsequently (Table 3 ).

Table 2 Variability in wood trait parameters of three sub-populations of $B$. serrata

\begin{tabular}{llll}
\hline Regions & GBH $(\mathrm{m})$ & WFL $(\mathrm{mm})$ & WFW $(\mathrm{mm})$ \\
Dhamtari (DT) & $0.99 \pm 0.25$ & $0.919 \pm 0.097$ & $0.025 \pm 0.001$ \\
Narayanpur (NP) & $1.07 \pm 0.22$ & $0.975 \pm 0.095$ & $0.026 \pm 0.002$ \\
Sarguja (SG) & $1.40 \pm 0.25$ & $1.009 \pm 0.120$ & $0.024 \pm 0.003$ \\
Average & $1.15 \pm 0.30$ & $0.968 \pm 0.11$ & $0.025 \pm 0.002$ \\
CV $(\%)$ & 26.01 & 11.36 & 8.75 \\
\hline
\end{tabular}

GBH = girth at breast height, WFL = wood fibre length, WFW = wood fibre width, CV = coefficient of variation, $\pm=$ standard deviation $(\mathrm{SD})$ 
Table 3 Genetic informativeness of RAPD and ISSR markers

\begin{tabular}{llllllll}
\hline $\begin{array}{l}\text { Marker } \\
\text { system }\end{array}$ & Primers & $\begin{array}{l}\text { Sequence } \\
\left(5^{\prime}-3{ }^{\prime}\right)\end{array}$ & N & AF & GD & PIC & RP \\
\hline \multirow{5}{*}{ RAPD } & OPA1 & CAGGCCGTTC & 12.0 & 0.77 & 0.32 & 0.26 & 6.10 \\
& OPA2 & TGCCGAGCTG & 13.0 & 0.72 & 0.37 & 0.29 & 10.80 \\
& OPY1 & GTGGCATCTC & 10.0 & 0.80 & 0.27 & 0.22 & 3.97 \\
& OPY2 & CATCGCCGCA & 12.0 & 0.87 & 0.19 & 0.16 & 3.70 \\
& OPP3 & CTGATACGCC & 9.0 & 0.87 & 0.21 & 0.18 & 2.97 \\
& Average & & 11.20 & 0.81 & 0.27 & 0.22 & 5.51 \\
& UBC840 & GAGAGAGAGAGAGAGAAT & 9.0 & 0.67 & 0.42 & 0.33 & 9.47 \\
& UBC830 & TGTGTGTGTGTGTGTGG & 6.0 & 0.74 & 0.36 & 0.29 & 6.50 \\
& UBC822 & TCTCTCTCTCTCTCTCA & 8.0 & 0.74 & 0.37 & 0.30 & 6.50 \\
& UBC845 & CTCTCTCTCTCTCTCTGG & 8.0 & 0.84 & 0.24 & 0.20 & 6.17 \\
& UBC836 & AGAGAGAGAGAGAGAGTA & 11.0 & 0.80 & 0.28 & 0.23 & 4.83 \\
\hline
\end{tabular}

$\mathrm{N}=$ number of amplified loci, $\mathrm{AF}=$ allele frequency, $\mathrm{GD}=$ gene diversity, $\mathrm{PIC}=$ polymorphic information content, $\mathrm{RP}=$ resolving power

\section{Genetic diversity and differentiation}

Among the non-Bayesian genetic diversity estimates of species population, $100 \%$ polymorphism, $0.26 \pm 0.17 \mathrm{GD}$ and $0.40 \pm 0.22$ I were observed among the regional locations (Table 4). For all measures, no significant difference was found among the three regions. Dhamtari was found slightly more diverse and polymorphic than the other two regions (Table 4); $\mathrm{G}_{\mathrm{ST}}$ was 0.31. The Bayesian model implemented in Hickory estimated the lowest DIC value (896.96) for the full model, and panmictic heterozygosity was $0.28 \pm 0.01$. No significant variation in panmictic heterozygosity was found among the three regional subpopulations (Table 4 ). The $\theta$-I, $\theta$-II, and $\theta$-III values were $0.50 \pm 0.04,0.45 \pm 0.04$ and $0.25 \pm 0.01$ subsequently, and $\mathrm{G}_{\mathrm{ST}}-\mathrm{B}$ was $0.33 \pm 0.02$.

The dendrograph based on Jaccard's genetic similarity coefficient (average 0.67 ) grouped the genotypes according to their regions (Figure 2). The genotypes sampled from Sarguja further bifurcated into two different but conjoint clusters supported by bootstrap values $>60$ (Figure 2). The PCoA accounting for $68.97 \%$ cumulative separation based on similar genetic distance separated the genotypes of Narayanpur from the rest of the sampled genotypes, and equal proportion of genotypes from Dhamatari and Sarguja was grouped separately, making an overall of four small clusters (Figure 3). The Bayesian
STRUCTURE program assigned $\mathrm{K}=2$ as the most appropriate number of cryptic population for the sampled genotypes based on the highest delta-K value in STRUCTURE HARVESTER. The bar plot generated shows admixing of genotypes assigned to the two cryptic populations $(K=2)$ with $>80 \%$ of ancestry coefficient (Figure 4 ). The genotypes from Dhamtari were found admixed with both cryptic populations, and the genotypes from Narayanpur and Dhamatri were assigned in the same cluster. On the other hand, genotypes from Sarguja clustered distinctly (Figure 4). The AMOVA showed $46.03 \pm 0.65 \%$ variation among groupings, given by dendrograph, PCoA and STRUTURE $(\mathrm{K}=2)$, with $53.38 \pm 0.15 \%$ variation within these groups. Mantel's test found significant $(\mathrm{p}<0.001)$ correlation between pairwise genetic and geographical distances among the genotypes.

\section{DISCUSSION}

The $B$. serrata, a member of the family Burseraceae, bifurcated from Terebinthaceae and Anacardiaceae during the Miocene epoch due to lesser intrinsic ability to adopt the changing conditions across the climatic niches (Weeks et al. 2014). Therefore, the distribution of genus Boswellia is limited within the mediterranian and tropical regions. Boswellia serrata is found only in central India and the species is renowned for its olio-gum-resin and pulp content. Due to 
Table 4 Population genetics parameters for 60 genotypes sampled from three sub-populations of B. serrata

\begin{tabular}{lrccc}
\hline Regions & P $\%$ & GD & I & Hs \\
\hline Dhamtari (DT) & 63.27 & $0.20 \pm 0.20$ & $0.30 \pm 0.28$ & $0.20 \pm 0.01$ \\
Narayanpur (NP) & 57.14 & $0.19 \pm 0.19$ & $0.28 \pm 0.28$ & $0.19 \pm 0.01$ \\
Sarguja (SG) & 55.10 & $0.14 \pm 0.16$ & $0.22 \pm 0.24$ & $0.17 \pm 0.01$ \\
Overall* & 100 & $0.26 \pm 0.17$ & $0.40 \pm 0.22$ & $0.28 \pm 0.01$ \\
\hline
\end{tabular}

$\pm=\mathrm{SD}, \mathrm{P} \%=$ polymorphism $\%$, GD $=$ Nei (1973) gene diversity, I = Shannon's information index, $\mathrm{Hs}$ = panmictic heterozygosity resulted by Hickory, *considering all 60 genotypes as a group

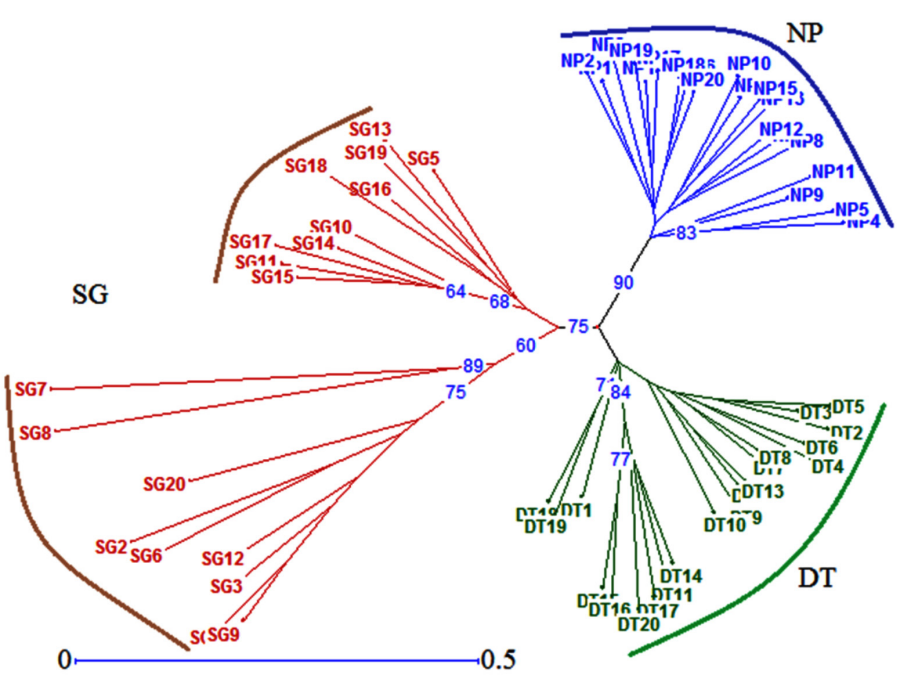

Figure 2 A Jaccard's similarity coefficient based radial dendrograph of 60 accessions from three natural populations i.e. Sarguja (SG), Dhamtari (DT) and Narayanpur (NP) of B. serrata; bootstrap values $(>60)$ are shown on nodes of accessions

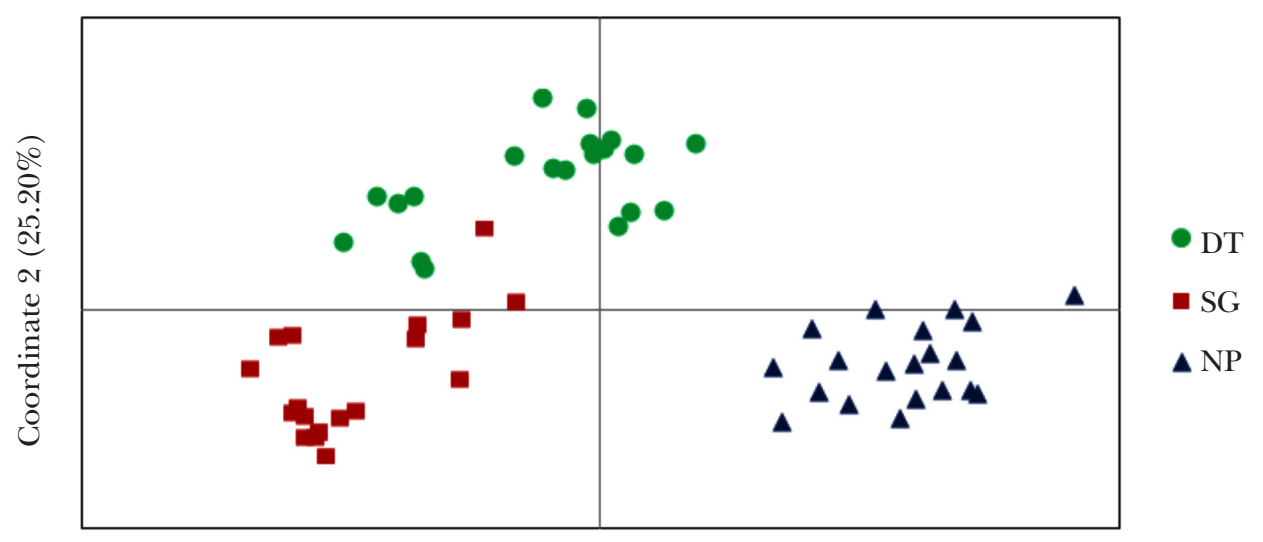

Coordinate $1(43.77 \%)$

Figure 3 The principal coordinate analysis, showing closeness of genotypes of $B$. serrata sampled from Dhamtari (DT), and Sarguja (SG), and the genotypes from Narayanpur (NP) cluster distinctly, in two coordinates covering $68.97 \%$ of variation 


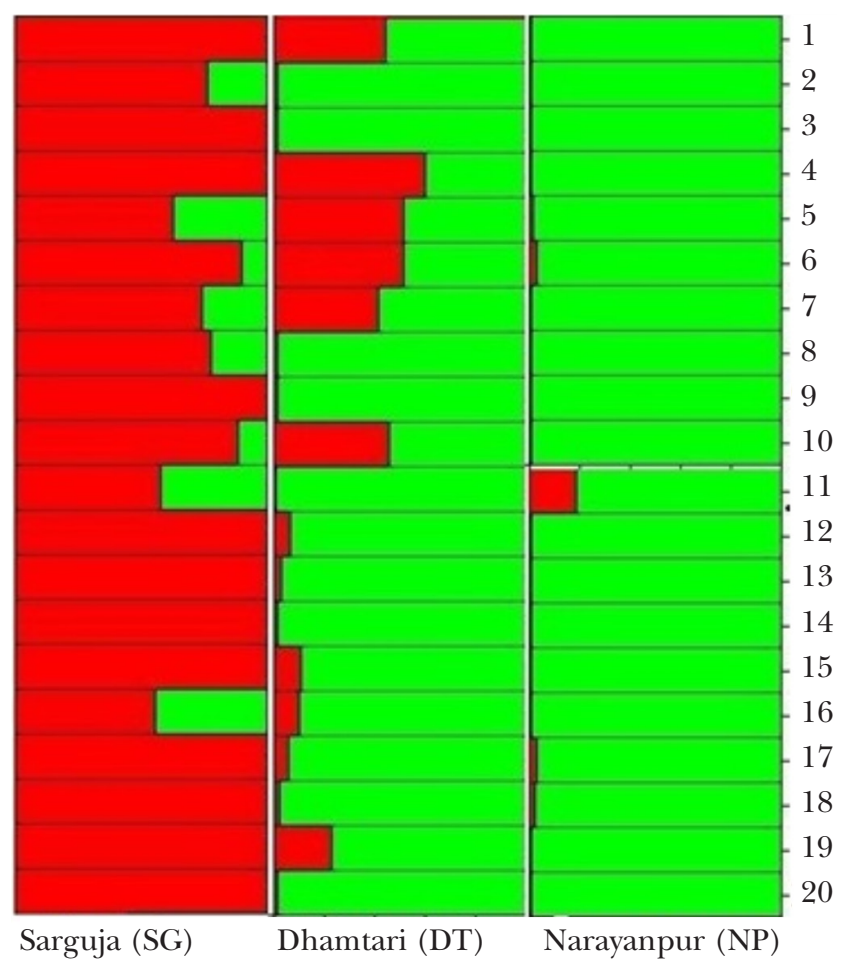

Figure 4 The Bayesian clustering resulted by program STRUCTURE depicted two cryptic populations (K) in 60 genotypes of $B$. serrata sampled from three locations of its natural distribution; each genotype is presented by a separate colored bar with corresponding number; green and red color represents two different cryptic populations.

uncontrolled harvesting it has become scarce in nature, and literature regarding its distribution is inadequate. During the investigation, the species was found in the temperature range of $19.02 \pm 6.35{ }^{\circ} \mathrm{C}$ to $33.02 \pm 4.07{ }^{\circ} \mathrm{C}$ with annual rainfall of $1595.33 \pm 95.30 \mathrm{~mm}$, confirming its suitability for moist conditions along arid regions. For molecular characterisation of the species, RAPD and ISSR markers were preferred due to the absence of background genomic information of the species, to design microsatellites and low-cost applicability. The problems with dominant markers such as low reproducibility and uncertain homology of alleles were handled during amplification and data profiling. Bayesian model-based $\theta$-statistics was applied based on successful estimation of the genetic variability and differentiation of population, applying dominant markers system in forest species (Holsinger \& Wallace 2004, Ci et al. 2008, Vaishnaw et al. 2015).

\section{Variation in wood fibre dimension}

The wood fibre length and thickness were considered to be the most important characteristics for mechanical strength of wood for the making of high-quality groundwood in paper industries (Zobel \& Jett 1995, Migneault et al. 2008). Comparison with other tropical trees employed in pulp making process established that wood fibre dimensions of B. serrata is much higher than Ailanthus altissima $(\mathrm{WFL}=0.747 \pm$ $0.035 \mathrm{~mm}$ and $\mathrm{WFW}=0.023 \pm 0.0004 \mathrm{~mm})$ and Eucalyptus globulus (WFL $=0.785 \pm 0.012 \mathrm{~mm}$ and $\mathrm{WFW}=0.018 \pm 0.0005)$ (Baptista et al. 2014) The WFL is lower than Eucalyptus grandis (1.01 \pm $0.14 \mathrm{~mm}$ ) (Bhat et al. 1990). The coefficient of variation of wood fibre dimension in $B$. serrata is higher than A. altissima (WFL $=4.76 \%$ and WFW $=1.66 \%)$ and E. globulus (WFL $=1.5 \%$ and $\mathrm{WFW}=$ $2.72 \%)$ and lower than $E$. grandis $(\mathrm{WFL}=14.45 \%)$ (Bhat et al. 1990, Baptista et al. 2014). In terms of adaptability, such high variation confirms the adaptive fitness of the population to local ecological conditions (Mac-Pherson et al. 2015).

\section{Genetic informativeness of the primers}

With an approach to handle the limitation of nonreproducibility, the dominant markers (RAPD/ ISSR) have exhibited moderate values for AF 
and GD. It indicates that the approach avoiding null alleles have controlled the informativeness of the primers, helping genetic differentiation (Lynch \& Milligan 1994). The AF exhibited by RAPD/ISSR markers are slightly higher to the information resulted in populations of Tectona grandis, sampled from India on ISSR markers $(0.73 \pm 0.02)$ (Vaishnav \& Ansari 2018). On the other hand, negligible differences in AF among the markers of RAPD and ISSR systems ensure the qualitative support for diversity assessment (Lynch \& Milligan 1994, Nybom \& Bartish 2000). The discriminatory power exhibit a strong and linear relationship between the ability of a primer to distinguish genotypes (Prevost \& Wilkinson 1999). The values of PIC and RP are comparable to those obtained with dominant markers in other species, e.g. Podophyllum hexandrum, Jatropha curcas and Pongamia pinnata (Naik et al. 2010, Grativol et al. 2011, Sharma et al. 2014).

\section{Genetic diversity and differentiation}

In order to estimate the genetic diversity of $B$. serrata population, both band-based and allele frequency-based approaches were applied with non-Bayesian and Bayesian statistics so that the under-estimation or over-estimation of the diversity measures, caused by the dominant marker systems, could be avoided. A significant correlation between diversity measures i.e. $\mathrm{P} \%$, GD, I and Hs, with slight differences among them for different regions, confirmed almost equal heterogeneity of the species population. The gene diversity of the sampled population has been found slightly higher than that reported by Nybom (2004) for out-crossing species (0.18). Nevertheless, Holsinger \& Wallace (2007) suggested avoiding comparison among diversity measures resulted by neutral markers (AFLP/RAPD), as these markers only show the differences in rates of mutations at their loci rather than reflecting different migration rates. However, there are few studies based on tree species of central Indian regions. Wang et al. (2011) investigated the genetic diversity of $D$. sissoo sampled from Indian regions and found $89.11 \%$ polymorphism, $0.27 \pm 0.16 \mathrm{GD}$ and $0.41 \pm$ 0.23 I. Ansari et al. (2012) sampled Tectona grandis from central and peninsular Indian regions and found $80.30 \%$ polymorphism, $0.32 \mathrm{GD}$ and 0.45 I. Comparison of results indicated that its natural distribution and level of genetic diversity were equally influenced by geographical conditions and landscapes. The significant correlation found between genetic and geographical distances of the genotypes in the study also supports this fact.

The genetic structure of a population reflects long-term evolutionary history of the species along with its mating system, reproductive biology and gene flow influenced by the adaptive selection and fragmentation (Slatkin 1987, Nybom \& Bartish 2000, Duminil et al. 2016). In this investigation, the results of Bayesian model-based analysis through HICKORY found full-model as the most suitable for the data, determining the influence of inbreeding within the populations. The low level of panmictic heterozygosity $(\mathrm{Hs})$ for different regions and overall population supports the finding. Like other out-crossing species, the B. serrata exhibited higher within-population variability than among populations, but the genetic variation within the population resulted by AMOVA was found comparatively lower than those reported in other out-crossing forest species (Hamrick \& Godt 1989, Nybom 2004, Wang et al. 2011, Ansari et al. 2012). The limited gene flow of $B$. serrata is one of the important factors that have led to the high differentiation among sampled populations and genotypes. The species has an entomophilous mode of pollination and self-incompatible flowers, supporting only cross-pollinated pollen to grow the pollen tubes. Moreover, only up to $10 \%$ fruit set has been observed in openpollination condition (Sunnichan et al. 2005). In the field observation, earlier abscission of unripe fruits and ripen fruit with empty seeds led to total absence of natural regeneration in all the sampling sites. These bottlenecks contributed to genetic drift and signatory inbreeding depression to the species population, reflected through different estimates.

The genetic differentiation measures, $\mathrm{G}_{\mathrm{ST}}$ and $\mathrm{G}_{\mathrm{ST}^{-}}-\mathrm{B}$, have resulted in comparatively equal values indicating the cautions taken to employ dominant markers for investigation, equivalent to Bayesian model correction. The $\theta$-statistic measures exhibit differences in their values due to low number of populations sampled for investigation (Holsinger $\&$ Wallace 2004). The $\theta$-I is equivalent to Wright's $\mathrm{F}_{\mathrm{ST}}$, and higher value $(0.50 \pm 0.04)$ is expected because of the scaled allele frequency measured across evolutionary time (Wright 1969). The $\theta$-II is a more appropriate measure for a small number of admixed population and its higher 
value $(0.45 \pm 0.004)$ reflects the problematic gene exchange among genotypes, leading to high differentiation.

The Bayesian clustering resulted by STRUCTURE, $K=2$, was found most suitable for the data on the basis of delta-K value. Nevertheless, the presence of inbreeding in sampled population and deviation from HWE suggest preference of dendrograph and PCoA over the two admixed cryptic populations resulted by the program STRUCTURE, due to its prior assumption of HWE. In PCoA, it was found that Sarguja population closely related to Dhamtari and Narayanpur population, representing itself distinctly even in geographical closeness to Dhamatri. This could be due to gene flow among populations following geographical limits and biological constraints. On the other hand, the Narayanpur population represented a different source of genetic origin of southern Indian region that could not be sampled. An almost equal polymorphism, genetic diversity and heterozygosity were found, but with highly differentiable genetic resource resulting to distinctly different clusters. This indicates that the sampled populations may belong to a large metapopulation of the species that has been fragmented with due course of time, due to its own intrinsic inability to cope with natural and anthropogenic pressures, later leading to geographical isolation.

The B. serrata is a highly out-crossing species with self-incompatibility and therefore, its own constraint to exchange the genes. The fragmentation of the population due to geographical isolation and commercial harvesting could be the reason for detected inbreeding pressure. The estimates of genetic diversity measures, genetic structure and level of differentiation of a species population depend on the molecular marker system employed for the investigation. In this investigation, the dominant markers could be a reason behind low to moderate estimates of gene diversity, panmictic heterozygosity and within-population variability. On the other hand, the Bayesian model-based analysis gave a higher value of $\theta$-II because the $\theta$-statistics has been developed specifically for the dominant markers and has been found more appropriate than $\mathrm{G}_{\mathrm{ST}}$ and $\mathrm{G}_{\mathrm{ST}} \mathrm{B}$ to estimate inbreeding and population differentiation (Holsinger et al. 2002, Spiegelhalter et al. 2002, Holsinger \& Wallace 2004). The comparatively higher variation in morphometric traits also indicate the existence of higher variability in population. The northernmost region, Sarguja and the southernmost region, Narayanpur represent different centers of genetic origin of a large metapopulation of the species. The genes from Sarguja have been immigrating to the central region, Dhamtari. For a better understanding of the influence of landscape and other geographical features on distribution and gene diversity of $B$. serrata, futher investigation should be conducted with a larger number of locations, representing its entire range of natural distribution, applying co-dominant multiallelic marker system to cross verify the results.

\section{CONCLUSION}

The B. serrata has been over-exploited due to its significant quality of wood for pulp and paper industries. The paper industries use the species as a raw material, and the oleo-gum-resin obtained from its wood has significant medicinal value to heal arthritis and asthma. The species is endemic to India and unfortunately, there is not a single source of sustainable supply for the raw material required in paper and pharmaceutical industries. Apart from all, the species is understudied and has not received much scientific attention on population genetic. The present investigation found the available genetic resource of the species in central Indian region maintaining high variation in wood fibre dimension and high genetic variability within and among sub-populations. In order to maintain the valuable forest genetic resource, the species need attention for conservation. The locations of its natural distribution can be conserved as nature reserves. A genetic improvement program should be initiated for selection and multiplication of elite genotypes. There is also a need to develop protocols for artificial generation of the species through clonal and tissue culture techniques.

\section{ACKNOWLEDGEMENT}

Authors are grateful to Director, Tropical Forest Research Institute, Jabalpur for institutional support and to Director General, Indian Council of Forestry Research and Education, Dehradun for financial support received under the project ID-175/TFRI/2011/Gen-4 (23). 


\section{REFERENCES}

Abuduli A, Aydin Y \& Sakiroglu M. 2016. Molecular evaluation of genetic diversity in wild-type mastic tree (Pistacia lentiscus L.). Biochemical Genetics 54: 619-635.

Ammon HP. 2006. Boswellic acid in chronic inflammatory disease. Planta Medica 72: 1100-1116.

Ansari SA, Narayanan C, Wali SA, Kumar R, Shukla N \& Kumar SR. 2012. ISSR markers for analysis of molecular diversity and genetic structure of Indian teak (Tectona grandis L f) locations. Annals of Forest Research 55: 1-13.

Baptista P, Costa AP, Simoes R \& Amaral ME. 2014. Ailanthus altissima: an alternative fibre source for papermaking. Industrial Crops and Products 52: 32-37.

BHat KM, BHAT KV \& DHAMODARan. 1990. Wood density and fibre length of Eucalyptus grandis grown in Kerala, India. Wood Fibre Science 22: 54-61.

BHAT RV, GUHA SRD \& PANDA SP. 1952. Indigenous cellulosic raw materials for the production of pulp, paper and board, part VIII — writing and printing papers from Boswellia serrata Roxb. (Salai). Indian Forester 78: 169-175.

Bonin A, Ehrich D \& Manel S. 2007. Statistical analysis of amplified fragment length polymorphism data: a toolbox for molecular ecologists and economists. Molecular Ecology 16: 3737-3758.

Ci X, Chen J \& Li Q. 2008. AFLP and ISSR analysis reveals high genetic variation and inert-population differentiation in fragmented populations of the endangered Litsea szemaois (Lauraceae) from Southwest China. Plant Systematics and Evolution 273: 237-346.

Deshmukh VP, Thakare PV, Chaudhari US \& Gawande PA. 2007. A simple method for isolation of genomic DNA from fresh and dry leaves of Terminalia arjuna (Roxb.) Wight and Argot. Electronic Journal of Biotechnology 10: 468-472.

Duminil J, Dainou K, Kaviriri DK, Gillet P, Loo J, Doucet JL \& HARDY OJ. 2016. Relationships between population density, fine-scale genetic structure, mating system and pollen dispersal in a timber tree from African rainforests. Heredity 166: 295-303.

Earl DA \& Vonholdt BM. 2012. Structure Harvester: a website and program for visualizing STRUCTURE output and implementing the Evanno method. Conservation Genetics Resources 4: 359-361.

EXCOFFIER L \& LISCHER HEL. 2010. ARLEQUIN Suite ver 3.5: A new series of programs to perform population genetics analyses under LINUX and WINDOWS. Molecular Ecology Notes 10: 564-567.

GHORPADE RP, ChOPRA A \& NiKAM TD. 2010. In vitro zygotic embryo germination and propagation of an edangered Boswellia serrata Roxb., a source of boswellic acid. Physiology and Molecular Biotechnology of Plants 16 (2): 159-165.

Grativol C, Da Fonseca Lira-Medeiros C, Hemerly aS \& FERREIRA PC. 2011. High efficiency and reliability of inter-simple sequence repeats (ISSR) markers for evaluation of genetic diversity in Brazilian cultivated Jatropha curcas L. accessions. Molecular Biology Reporter 38: 4245-4256.

HAMrick JL \& GodT MJW. 1989. Allozyme diversity in plant species. Pp 43-63 in Brown AHD et al. (eds) Plant
Population Genetics: Breeding and Genetic Resources. Sinauer, Sunderland.

Holsinger KE, Lewis PO \& Dey DK. 2002. A Bayesian approach to inferring population structure from dominant markers. Molecular Ecology 11: 1157-1164.

Holsinger KE \& Lewis PO. 2007. Hickory: A Package for Analysis of Population Genetic Data, Version 1.1. Computer Program and Documentation. Department of Ecology and Evolutionary Biology, University of Connecticut, Storrs, Connecticut.

Holsinger KE \& WaLlace LE. 2004. Bayesian approach for analysis of population structure: an example from Planthanthera leucophaea (Orchidaceae). Molecular Ecology 13: 887-894.

KHAN MAW. 1972. Propagation of Boswellia papyrifera through branch-cuttings. Indian Forester 98: 437-440.

KHARE CP. 2004. Encyclopedia of India, Rational Western Therapy, Ayurvedic and other Traditional Usage, Botany. Springer, Berlin.

LIU K \& Muse SV. 2005. POWERMARKER: integrated analysis environment for genetic marker data. Bioinformatics 21: 2128-2129.

LinCH M \& MiLLIGAN BG. 1994. Analysis of population genetic structure with RAPD markers. Molecular Ecology 3: 91-99.

Mag-Pherson A, Hohenlohe PA \& Nuismer SL. 2015. Trait dimensionality explains widespread variation in local adaptation. Proceedings of the Royal Society of London B 282: 20141570.

Mahesh S, Kumar P \& Ansari SA. 2015. A rapid and economical method for the maceration of wood fibres in Boswellia serrata Roxb. Tropical Plant Research 2: 108-111.

Migneault S, Koubaa A, Erchiqui F, ChaAla A, Englund K, Krause C \& Wolcott M. 2008. Effect of fibre length on processing and properties of extruded woodfibre/HDPE composites. Journal of Applied Polymer Science 110: 1085-1092.

Miller MP. 2005. Alleles in space: computer software for the joint analysis of inter-individual spatial and genetic information. Journal of Heredity 96: 722-724.

Naik PK, Alam A, Singh H, Goyal V \& Parida S. 2010. Assessment of genetic diversity through RAPD, ISSR and AFLP markers in Podophyllum hexandrum: a medicinal herb from the Northwestern Himalayan region. Physiology and Molecular Biology of Plants 16: 135-148.

Nybom H \& Bartish IV. 2000. Effects of life history traits and sampling strategies on genetic diversity estimates obtained with RAPD markers in plants. Perspectives in Plant Ecology Evolution and Systematics 3: 93-114.

Nувом HD. 2004. Comparison of different nuclear DNA markers for estimating intraspecific genetic diversity in plants. Molecular Ecology 13: 1143-1155.

Pawar GV, Singh L, Jhariya MK \& SahU KP. 2012. Regeneration status in relation to antropogenic disturbance in tropical deciduous forest of Chhattisgarh. Ecoscan 1: 281-286.

Peakall R \& Smouse PE. 2012. GenAlEx 6.5: genetic analysis in Excel. Population genetic software for teaching and research-an update. Bioinformatics 28: 2537-2539.

Perrier X \& Jacquemoud-Collet JP. 2006. DARwin software. http://darwin.cirad.fr/. 
Prevost A \& Wilkinson MJ. 1999. A new system of comparing PCR primers applied to ISSR fingerprinting of potato cultivars. Theoretical and Applied Genetics 98: 107-112.

Pritchard JK, Stephens M \& Donnelly P. 2000. Inference of population structure using multilocus genotype data. Genetics 155: 945-959.

Purohit SD, Sharma P \& Nagori R. 1995. Assessment of molecular diversity and Invitro clonal fidelity in some Indian medicinal plants. ISHS Acta Horticulturae 1098: 47-60.

Shah SA, Rathod IS, Suhagia BN, Pandya SS \& Parmar VK. 2008. A simple high performance liquid chromatography for the estimation of boswellic acids from the market formulations containing Boswellia serrata extract. Journal of Chromatography Science 46: $735-738$.

SHARMA S. 1983. A census of rare and endemic flora of South East Rajasthan. Pp 630-670 in Jain SK \& Rao RR (eds) Threatened Plants of India. Botanical Survey of India, Howrah.

Sharma SS, Aadil K, Negi MS \& Tripathi SB. 2014. Efficacy of two dominant marker systems, ISSR and TE-AFLP for assessment of genetic diversity in biodiesel species Pongamia pinnata. Current Science 106: 1576-1580.

Sharma YK, Bhandari KS \& SRIVAstava A. 1985 Boswellia serrata resin gum: a potential internal sizing agent for paper. Indian Forester 111: 149-157.

SLATKIN M. 1987. Gene flow and the geographic structure of populations. Science 236: 787-792.

Spiegelhalter DJ, Best NG, Carlin BP \& Van Der Linde A. 2002. Bayesian measures of model complexity and fit. Journal of Royal Statistical Society Series B Statistical Methodology 64: 583-689.
Sunnichan VG, Mohanram HY \& Shivanna KR. 2005. Reproductive biology of Boswellia serrata, the source of salai guggul, an important gum-resin. Botanical Journal of Linean Society 147: 73-82.

VAishnaV V \& Ansari SA. 2018. Genetic differentiation and adaptation in teak (Tectona grandis L.f.) metapopulations. Plant Molecular Biology Reporter. doi: 10.1007/s11105-018-1101-3.

Vaishnav V, Mohammad N, Wali SA, Kumar R, Tripathi SB, NEGI MS \& ANSARI SA. 2015. AfLP markers for analysis of genetic diversity and structure of teak (Tectona grandis L f) in India. Canadian Journal of Forest Research 44: 297-306.

WANG BY, ShI L, RUAN ZY \& DENG J. 2011. Genetic diversity and differentiation in Dalbergia sissoo (Fabaceae) as revealed by RAPD. Genetics and Molecular Research 10: 114-120.

Weeks A, Zapata F, Pell SK, Daly DC, Mitchell JD \& Fine PVA. 2014. To move or to evolve: contrasting patterns of intercontinental connectivity and climatic niche evolution in Terbinthaceae (Anacardeacea and Burseraceae). Frontier Genetics. doi: 10.3389/ fgene.2014.0 0409 .

Wright S. 1969. Evolution and the Genetics of Populations, Volume 2: The Theory of Gene Frequencies. University of Chicago, Chicago.

Yeh FC, Yang RC \& Boyle T. 1999. POPGENE 32-version 1.32. Software. http://www.ualberta.ca/ fyeh/fyeh/.

Zietkiewiez E, Rafalski A \& Labuda D. 1994. Genome fingerprinting by simple sequence repeat (SSR)anchored polymerase chain reaction amplification. Genomics 20: 176-183.

Zobel B \& Jetт JB. 1995. Genetics of Wood Production. SpringerVerlag, New York. 